\title{
OPTIMAL ALLOCATION OF LAND AND WATER RESOURCES IN IRRIGATED AGRICULTURE BY MEANS OF GOAL PROGRAMMING: APPLICATION IN LOUDIAS RIVER BASIN
}

\section{LATINOPOULOS* Y. MYLOPOULOS}

Department of Civil Engineering

Aristotle University of Thessaloniki GR 541 24, Thessaloniki,Greece

*to whom all correspondence should be addressed: e-mail: dlatino@civil.auth.gr
Selected from papers presented in $9^{\text {th }}$ International Conference on Environmental Science and Technology (9CEST2005)

1-3 September 2005, Rhodes island, Greece

\begin{abstract}
Agriculture is an economic activity that contributes significantly to the gross national product of a country, securing at the same time the viability of the rural sector and the social coherence. On the other hand, it can generate an environmental externality, especially concerning water resources that, in the name of higher crop productivity, are often overexploited or polluted. Most agricultural decision analysis studies are primarily focusing on farmers' welfare optimization. Therefore, this externality is only examined as a negative environmental effect of different farming and agricultural policy scenarios. However, a proper decision analysis in the field of agricultural policy should be guided by the goal of finding a unique "optimal" solution out of a great number of possible alternatives that arise from a complex integrated socio-economic and environmental system, which incorporates significant conflicted interests.

The main objective of this paper is to create, apply and evaluate a model that aims at the simultaneous maximization of farmer's welfare and the minimization of the consequent environmental burden. More specifically, weighted and lexicographic goal programming techniques are employed. These techniques are implemented on a representative area in the Loudias River Basin in Greece to seek for a compromising solution - in terms of area and water allocation (under different crops) - resulting in figures that will come as close as possible to the decision maker's economic, social and environmental goals.

The information that is incorporated into the selected goals includes farmers' welfare, characterized by securing income and employment levels, as well as environmental benefits, such as water resources protection from excessive application of fertilizers and from unsustainable use of irrigation water. Several weights or priority levels can be assigned on these goals, according to the intentions of the decision maker, that are likely to differentiate the final allocation of resources. Hence, the analysis is undertaken under different policy scenarios (e.g. environmental friendly, farmers' friendly and compromising scenarios) and the results are well elucidated. In addition, it is further examined the different final outcome that may arise when the targets of the various economic and environmental goals are relaxed in order to reduce the information bias from the decision maker as well as to better perceive the indirect relationship between some competitive goals.
\end{abstract}

KEY WORDS: agriculture, resource allocation, irrigated agriculture, multicriteria analysis, weighted goal programming, lexicographic goal programming, sensitivity analysis. 


\section{INTRODUCTION}

During the last decades, agricultural decision analysis studies have been primarily focused on farmers' welfare maximization. The reasoning is that the prosperity of the agricultural sector is very crucial for the national economy but also for the regional development. However, this prosperity has quite often a significant environmental cost in terms of water resources overexploitation or pollution. For this reason there is a stressing need to formulate decision-making models in agricultural planning that will recognize the multiplicity of objectives and goals and that will seek for "optimal" solutions in a complex socio-economic and environmental system. These optimal solutions could result from the use of multicriteria analysis and they are actually solutions that satisfy the decision maker [1]. Agricultural planning, depending on policy aims and decision makers' objectives, may have either the form of whole farm planning or of regional planning. Regional agricultural planning covers a larger area and has a wider range of characteristics, which are directly or indirectly connected with farming activities and should be taken into consideration in decision making. Thus, the following multicriteria analysis is applied on this level.

\section{THEORETICAL FRAMEWORK}

\subsection{Goal programming and agricultural planning}

Goal Programming is one of the oldest multicriteria decision making techniques and perhaps the most frequently used one in agricultural planning. Its general aim is to optimize several goals and at the same time to minimize the deviation for each of the objectives from the desired targets. A goal has the following general form:

where,

$$
F_{a}(x)+n_{a}-p_{a}=g_{a}
$$

\begin{tabular}{l|l}
$\mathrm{F}_{\mathrm{a}}(\mathrm{x})=$ attribute & $\mathrm{n}_{\mathrm{a}}=$ negative deviational variable \\
$\mathrm{g}_{\mathrm{a}}=$ target & $\mathrm{p}_{\mathrm{a}}=$ positive deviational variable
\end{tabular}

It is advisable to be very selective regarding the number of objectives modeled, avoiding those that are closely related (for example, sales are closely related to gross margin) [2]. Most agricultural decision making studies are focusing on farmers welfare (utility) optimization and are using the goal programming techniques to satisfy economic, social and managerial criteria originated only from the farmers viewpoint [2], [3], [4]. On the other hand, the aim of this study is to formulate a decision-making model for the policy maker that intends to satisfy both farmers' welfare and environmental sustainability. For this reason, five objectives were defined (Table 1). In relation with the farmers, three of the most frequent used objectives were chosen (Goals 1-3 in Table 1): a) maximum profit, b) minimum labor requirements and c) minimum risk on farmers' income.

Profit is approximated by means of gross margin (GM), which in the short run is a good estimator of it [5]. On the other hand, the attribute of labor is estimated as the total time (in hours) that is necessary for the cultivation of all crops in the reference area. It is worth noting that the minimization of labor is sometimes opposed to social policies that are trying to safeguard the occupation in the primary sector and especially in agriculture, in order to ensure social stability and coherence in rural areas. Thus, the decision maker should pay attention that the total labor will not be substantially decreased and should be also ready, if necessary, to trade off some working hours with the rest of the goals.

The risk on farmers' income, in most studies, is measured as the variance of total gross margin, that is:

$$
\overrightarrow{\mathrm{X}}_{\mathrm{i}}^{\mathrm{t}}[\operatorname{Cov}] \overrightarrow{\mathrm{X}}_{\mathrm{i}}
$$

where [Cov] is the variance - covariance matrix of gross margin for several observations. However, variance, as a measure of risk, according to Markowitz Index assumes that the 
negative semivariance is equal to the positive semivariance, which in many practical situations is not satisfied. A more reliable way to measure the individual variability attached to different crops is by means of the negative semivariance (NSV) [6]. Thus, the sum of individual negative semivariances is chosen as the third goal of the model.

$$
\mathrm{NSV}_{\mathrm{i}}=\frac{\sum_{\mathrm{j}}^{\mathrm{k}}\left(\mathrm{GM}_{\mathrm{ij}}-\overline{\mathrm{GM}}_{\mathrm{i}}\right)^{2}}{\mathrm{k}} \mid \mathrm{GM}_{\mathrm{ij}} \leq \overline{\mathrm{GM}_{\mathrm{i}}}
$$

where,

$\mathrm{j}=$ observation

$\mathrm{k}=$ number of observations

$$
\mid \begin{aligned}
& \mathrm{GM}_{\mathrm{ij}}=\text { gross margin for crop } \mathrm{i} \text { and observation } \mathrm{j} \\
& \overline{\mathrm{GM}}_{\mathrm{i}}=\text { average gross margin for crop } \mathrm{i}
\end{aligned}
$$

Regarding the environment, quite a few past studies included some environmental objectives, but they rarely focused on water and fertilizer consumption [7]. Besides, in most cases, these attributes are treated only as negative effects of various farming and agricultural policy scenarios and not as main objectives in agricultural planning. However, in this study water and nitrogen attributes are included in the goal system as goals equivalent to the socioeconomic ones (Goals 4 and 5 in Table 1).

According to Psychoudakis et al. [8] environmentally favorable management of farming means different farming practices or cropping patterns. The latter is feasible under Mediterranean conditions that allow a wide range of cropping patterns. Therefore, the control variables $\left(\mathrm{X}_{\mathrm{i}}\right)$ for this model are the cultivated hectares for every actual or potential crop in the study area.

Table 1. Goal Matrix

\begin{tabular}{ll}
\hline $1^{\text {st }}$ Goal: Gross margin & {$\left[\sum_{\mathrm{i}}^{\mathrm{m}} \mathrm{GM}_{\mathrm{i}} \cdot \mathrm{X}_{\mathrm{i}}\right]+\mathrm{n}_{1}-\mathrm{p}_{1}=\mathrm{g}_{1}$} \\
$2^{\text {nd }}$ Goal: Total labor input & {$\left[\sum_{\mathrm{i}}^{\mathrm{m}} \mathrm{L}_{\mathrm{i}} \cdot \mathrm{X}_{\mathrm{i}}\right]+\mathrm{n}_{2}-\mathrm{p}_{2}=\mathrm{g}_{2}$} \\
$3^{\text {rd }}$ Goal: Total negative semivariance - Risk & {$\left[\sum_{\mathrm{i}}^{\mathrm{m}} \mathrm{NSV}_{\mathrm{i}} \cdot \mathrm{X}_{\mathrm{i}}\right]+\mathrm{n}_{3}-\mathrm{p}_{3}=\mathrm{g}_{3}$} \\
$4^{\text {th }}$ Goal: Total irrigation water input & {$\left[\sum_{\mathrm{i}}^{\mathrm{m}} \mathrm{IW}_{\mathrm{i}} \cdot \mathrm{X}_{\mathrm{i}}\right]+\mathrm{n}_{4}-\mathrm{p}_{4}=\mathrm{g}_{4}$} \\
$5^{\text {th }}$ Goal: Total nitrogen input & {$\left[\sum_{\mathrm{i}}^{\mathrm{m}} \mathrm{N}_{\mathrm{i}} \cdot \mathrm{X}_{\mathrm{i}}\right]+\mathrm{n}_{5}-\mathrm{p}_{5}=\mathrm{g}_{5}$} \\
\hline
\end{tabular}

where,

$\mathrm{X}_{\mathrm{i}}=$ total area devoted to crop $\mathrm{i}$

$\mathrm{IW}_{\mathrm{i}}=$ annual volume of irrigation water to maximize the productivity of crop i

$\mid \begin{gathered}L_{i}=\text { labor input for crop } i \\ N_{i}=\begin{array}{c}\text { suggested nitrogen quantity to maximize } \\ \text { the productivity of crop } i\end{array}\end{gathered}$

A general aim for the first three goals is that, more or less, goal programming will safeguard the current observed values in the reference area. This is a prerequisite for the integrated management to be accepted and adopted. Future model resolutions may also intend to ameliorate farmers' welfare by selecting targets at higher levels than the current ones. Besides, for the present, the emphasis is put on the abatement of the environmental burden from irrigated agriculture. Thus, the target of total irrigation water input aims to a $15 \%$ reduction of today's water consumption, while the total nitrogen input should be restricted to $170 \mathrm{~kg} / \mathrm{ha}$ ( $21 \%$ less than the actual situation), to conform to 
the European Nitrate Directive 91/676/EEC. The model also comprises a set of cropping pattern constraints such as: total arable area, rotational and agronomic considerations, market and CAP limitations.

The pay-off matrix (Table 2) shows the results of the individual optimization of each objective. The main diagonal contains the five independent optima for the corresponding objectives and can be used as an indicator of the degree of conflict among the different criteria. In the extreme case where all objectives are closely related (the optimization of an objective implies optimal values for the rest) there is no further need to formulate a multi-criteria model. According to the second and third column of Table 2, there is a quite significant compatibility between the objectives of labor and risk. In addition, it is obvious that the maximization of farmers' income (gross margin function) has strong conflict with all the other objectives. The last column represents the corresponding values of the five objectives according to the actual crop distribution in order to see the distance between the real situation and each individual optimization.

Table 2. Pay-off Matrix

\begin{tabular}{|c|c|c|c|c|c|c|}
\hline & \multicolumn{5}{|c|}{ Optimum values (per ha) } & \multirow[t]{2}{*}{ Actual values } \\
\hline & GM & LAB & NSV & WAT & FER & \\
\hline GM & 3,930 & 2,125 & 2,118 & 2,382 & 2,397 & 3,496 \\
\hline LAB & 701 & 403 & 415 & 485 & 452 & 630 \\
\hline NSV & 97,648 & 44,798 & 43,717 & 62,852 & 64,773 & 84,800 \\
\hline WAT & 7,583 & 5,937 & 5,936 & 5,799 & 5,949 & 6,900 \\
\hline FER & 204 & 177 & 175 & 189 & 149 & 214 \\
\hline
\end{tabular}

There are several schemes that could be applied in order to solve the above-formulated goal-programming problem (e.g. Lexicographic, Minimax, Weighted, Extended, Interval). Among them, weighted goal programming (WGP) and lexicographic goal programming (LGP) were selected for this study. As Tamiz et al. [9] show, these two techniques represent the $86 \%$ of all goal programming applications reported in the literature $(65 \%$ use LGP and $21 \%$ WGP). The difference among these options - as it will be displayed in the following - lies on their achievement functions. To facilitate the implementation of the methodology, a computer software program called MOPEN was used, which is specially designed as a tool for Linear Multiobjective and Goal programming problems [10].

\subsection{Weighted Goal Programming}

WGP considers all goals simultaneously within a composite objective function comprising the sum of all respective deviations of the goals from their aspiration levels. The deviations are then weighted according to the relative importance of each goal, $w_{a}$ [11]. To avoid the possible bias effect of the solutions due to different measurement units of goals, percentage normalization takes place (i.e. the model minimizes the sum of the percentage deviations from the targets). So, in the problem that is under consideration, the composite objective (achievement) function has the following form:

$$
\text { Min } \quad z=w_{1} \frac{n_{1}}{g_{1}} \cdot 100+w_{2} \frac{p_{2}}{g_{2}} \cdot 100+w_{3} \frac{p_{3}}{g_{3}} \cdot 100+w_{4} \frac{p_{4}}{g_{4}} \cdot 100+w_{5} \frac{p_{5}}{g_{5}} \cdot 100
$$

subject to

$$
\text { Eq (4) - Eq (8) }
$$

$\underline{\mathrm{X}} \in \underline{\mathrm{F}}$ (Cropping pattern constraints concerning crop rotation, market and CAP limitations)

$X_{i} \geq 0$

$\mathrm{n}_{\mathrm{j}}, \mathrm{p}_{\mathrm{j}} \geq 0$

$$
(j=1,2, \ldots 5)
$$

Although decision makers' preference over each objective compared to another would give a better picture of the weight, they can be judged by assigning differential weights 
from both the government and farmers' viewpoints [12]. For this reason, three different policy scenarios are examined by assigning a diverse set of weights in each case (Table 3). Namely, an environmental friendly scenario, a farmers' friendly (economic) scenario and, finally, a compromising scenario are analysed in order to infer the trade-offs between farmers' welfare and environmental sustainability, but also in order to estimate the abatement in each goal (deviation) that is necessary for a compromising solution. Gross margin and total irrigation water consumption are considered as the most important objectives in the economic and environmental scenario respectively, while equal weights are assigned to all objectives in the compromising one.

Table 3. Goal weights under the three policy scenarios

\begin{tabular}{lccc}
\hline & Economic scenario & Environmental scenario & Compromising scenario \\
$\mathrm{w}_{1}$ & 0.40 & 0.15 & 0.20 \\
$\mathrm{w}_{2}$ & 0.25 & 0.10 & 0.20 \\
$\mathrm{w}_{3}$ & 0.15 & 0.10 & 0.20 \\
$\mathrm{w}_{4}$ & 0.10 & 0.40 & 0.20 \\
$\mathrm{w}_{5}$ & 0.10 & 0.25 & 0.20 \\
\hline
\end{tabular}

\subsection{Lexicographic goal programming}

The lexicographic method is based on the logic that in some decision making systems some goals seems to prevail. Pre-emptive weights are attached to the sets of goals, which are classified in different priorities. The procedure begins with comparing all the alternatives with respect to the higher priorities goals and continues with the next priority until only one alternative is left. In other words, the fulfillment of a set of goals that is situated at a certain priority is immeasurably preferable to the achievement of any other set placed at a lower priority [11]. Because of this characteristic, there are no alternative optima if a higher priority could not be satisfied and excessive prioritization of goals can possibly lead to unrealistic models. So, the goals should be divided into a small number of pre-emptive priorities [13]. In this model, as it is already noted, there are two main policies (economic and environmental), which are depicted in the initial goal system and the WGP. Each policy may constitute a priority level if the decision maker had a strong preference to it. Thus, the set of five goals is divided into two pre-emptive priorities that will alternately take the first and second place in the minimization process:

$$
\begin{array}{ll}
\text { Economic scenario (2 priority levels): } & \text { Min } z=\left[\left(n_{1}+p_{2}+p_{3}\right),\left(p_{4}+p_{5}\right)\right] \\
\text { Environmental scenario (2 priority levels): } & \text { Min } z=\left[\left(p_{4}+p_{5}\right),\left(n_{1}+p_{2}+p_{3}\right)\right]
\end{array}
$$

subject to the same goals and constraints as in weighed goal programming

One of the drawbacks of LGP is its assumption that trade-offs between goals can take place within a given priority but they cannot be traded-off across the boundaries of different priorities. However, the concurrent implementation of WGP ensures the examination and investigation of all the possible trade-offs. On the other hand, it is a technique less prone to subjectivity than the WGP, as there is no need to assign weights to each objective but only to define the ordering of preferences.

\section{RESULTS AND DISCUSSION}

\subsection{Description of the study area}

The Loudias River Basin, located in Northern Greece, was selected as the study area because it is a representative area of intensive irrigated agriculture (agriculture is the main economic activity and the major water consumer). According to Berbel and Rodriguez-Ocana [5], the study area should be large enough to contain a significant number of farmers but not as large as to introduce sources of variation in soil, climate or market conditions. Therefore the river basin was divided into several clusters according to 
the characteristics of the average farm in each sub-region and especially according to the cropping pattern. The selected cluster (Figure 1) is the cluster with the greater and most significant trade-offs among the five aforementioned objectives. It is situated on the west side of the river basin and has a total agricultural area of 5,908 hectares, farmed by roughly 4,000 irrigators. The main cultivations are peach-trees and corn. Irrigation water is consumed at an annual average rate of $6,900 \mathrm{~m}^{3} \mathrm{ha}^{-1}$ (further information on other attributes is provided at the far right column of Table 4).

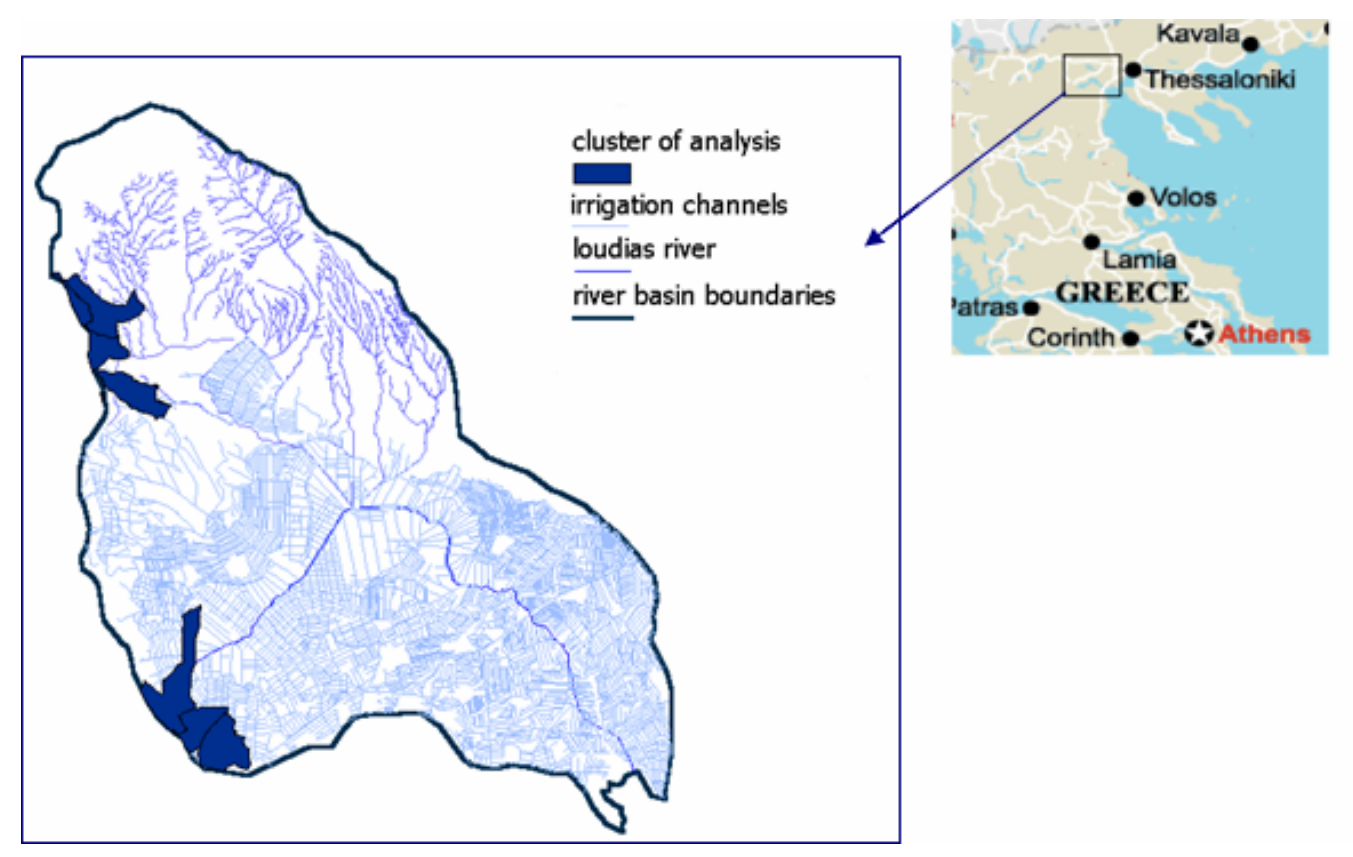

Figure 1. Map of the study area

\subsection{Comparison of WGP and LGP results}

Table 4 depicts the results of all the scenarios in lexicographic and weighted goal programming. More precisely, it displays the goal values and the deviational variables in per-hectare basis. In addition it cites the current values of each attribute in order to better assess the results. It is clear that both economic scenarios (first and fourth column) end up to the same solution, which satisfies the three associated goals without any deviation. It is also worthwhile to mention that even in these farmer-oriented scenarios the environmental attributes are improving in relation to the status quo. However their values are still away from the selected targets $(12.5 \%$ more water and $10.5 \%$ more nitrogen input).

On the other hand, the environmental scenarios (second and fifth column) are slightly different but they both satisfy the water and nitrogen goals. The only target that these scenarios can't meet is the gross margin one, which, in both cases is almost $20 \%$ less than the desired level. So, it is obvious that the main trade-offs are between gross margin and the two environmental goals (especially between gross margin and irrigation water). Hence, if the decision maker wishes an integrated agricultural management, then the compromising solution seems to be a quite acceptable one, as the final deviations from the aspiration levels are confined enough.

In Table 5 is illustrated the resultant cropping pattern under the different scenarios and methodology choice. The economic scenarios are closer than the others to the real situations. This is a more or less expected outcome because: a) the crop decisions are influenced by farmers' welfare maximization, b) irrigation water charges are until now totally uncorrelated with water consumption (a fee is paid only in a per hectare basis) 
[14], and c) the Nitrate Directive is not yet implemented in this area. The main cropping alternation between the different scenarios is the replacement of peach-trees with cereals (barley in this example). This is a difficult and time-consuming process, as it is going to differentiate the whole existing farming system in the area, which is currently based on peaches monoculture.

Table 4. Goal programming results

\begin{tabular}{|c|rrrrr|r|}
\hline & \multicolumn{8}{|c|}{ Weighted Goal Programming } & \multicolumn{3}{c|}{ Lexicographic } & \multicolumn{1}{c|}{ Status quo } \\
\cline { 2 - 7 } & Economic & Environmental & Compromising & Economic & Environmental & Observed values \\
\hline GM & $3,400.0$ & $2,760.2$ & $2,905.6$ & $3,400.0$ & $2,763.3$ & $3,496.1$ \\
LAB & 598.1 & 492.8 & 504.2 & 598.1 & 498.3 & 630.0 \\
NSV & $84,800.0$ & $72,204.5$ & $79,929.7$ & $84,800.0$ & $67,745.9$ & $84,800.0$ \\
WAT & $6,634.9$ & $5,900.0$ & $6,079.2$ & $6,634.9$ & $5,900.0$ & $6,900.0$ \\
FER & 187.7 & 170.0 & 170.0 & 187.7 & 170.0 & 214.9 \\
\hline \multicolumn{7}{|c}{ Goal values (per hectare) } \\
\hline $\mathbf{n}_{\mathbf{1}}$ & 0 & 639.8 & 494.4 & 0 & 636.7 & 0 \\
$\mathbf{p}_{\mathbf{2}}$ & 0 & 0 & 0 & 0 & 0 & 0 \\
$\mathbf{p}_{\mathbf{3}}$ & 0 & 0 & 0 & 0 & 0 \\
$\mathbf{p}_{\mathbf{4}}$ & 734.9 & 0 & 179.2 & 734.9 & 0 & 0 \\
$\mathbf{p}_{\mathbf{5}}$ & 17.7 & 0 & 0 & 17.7 & 0 & 950.0 \\
\hline
\end{tabular}

Table 5. Decision variables results

\begin{tabular}{|l|rrrrr|r|}
\hline & \multicolumn{7}{|c|}{ Weighted Goal Programming } & \multicolumn{2}{c|}{ Lexicographic } & Status quo \\
Economic & Environmental & Compromising & Economic & Environmental & (tatus \\
\cline { 2 - 7 } Peach-trees & 70.57 & 50.98 & 56.21 & 70.57 & 51.15 & 82.00 \\
Barley & 19.05 & 30.00 & 30.00 & 19.05 & 30.00 & 5.20 \\
Sugar beets & 0.50 & 4.52 & 0.50 & 0.50 & 5.26 & 0.83 \\
Apple-trees & 2.39 & 3.95 & 5.00 & 2.39 & 2.50 & 0.67 \\
Vineyards & 0.00 & 2.50 & 0.00 & 0.00 & 1.59 & 0.30 \\
Cotton & 0.00 & 2.00 & 0.00 & 0.00 & 2.00 & 0.50 \\
Vegetables & 2.00 & 2.00 & 2.00 & 2.00 & 2.00 & 2.10 \\
Melons & 1.50 & 1.50 & 1.50 & 1.50 & 1.50 & 0.75 \\
Tobacco & 1.50 & 1.50 & 1.50 & 1.50 & 1.50 & 0.50 \\
Other trees & 2.50 & 1.05 & 0.00 & 2.50 & 2.50 & 1.25 \\
Alfalfa & 0.00 & 0.00 & 3.29 & 0.00 & 0.00 & 2.00 \\
\hline
\end{tabular}

\subsection{Sensitivity analysis}

One weakness of LGP is that it could lead to non-rational decisions in cases when the decision maker is not fully informed or confident about the targets, the weights, the priority levels and the ordering of preferences. For this reason the implementation of a sensitivity analysis is often recommended. Two different types of sensitivity analysis were performed. First of all, the priority levels were increased from two to five. Every objective now constitutes a priority level. Then they were re-arranged in a way that assures that the economic goals would either be all higher or all lower than the environmental ones:

Economic approach

Environmental approach
$\operatorname{Lex}_{1} \quad \mathrm{z}=\{\underbrace{\left[\left(\mathrm{n}_{1}\right),\left(\mathrm{p}_{2}\right),\left(\mathrm{p}_{3}\right)\right]}_{\mathrm{T}_{3}}, \underbrace{\left[\left(\mathrm{p}_{4}\right),\left(\mathrm{p}_{5}\right)\right]}_{\mathrm{T}_{2}}\}$

$$
\operatorname{Lex}_{2} \quad \mathrm{z}=\left\{[\underbrace{\left[\left(\mathrm{p}_{4}\right),\left(\mathrm{p}_{5}\right)\right]}_{\mathrm{T}_{2}}, \underbrace{\left[\left(\mathrm{n}_{1}\right),\left(\mathrm{p}_{2}\right),\left(\mathrm{p}_{3}\right)\right]}_{\mathrm{T}_{3}}\}\right.
$$


$T_{j}=$ possible transpositions of goals into brackets $\left(T_{2}=2, T_{3}=6\right)$

So, twelve possible re-arrangements were analyzed in each scenario, but only three different final solutions arose (Table 6). The economic scenarios end up with two solutions (Case I and Case II) that differ on the priorities of the environmental objectives. As a result the main variations are observed on total water and nitrogen inputs. Concerning now the environmental scenarios, they all give the same resolution (Case III), which is identical with the case of a two-priority levels analysis (Table 4).

Table 6. Results for different priority levels in lexicographic goal programming

\begin{tabular}{lrrr} 
& \multicolumn{1}{c}{ Case I } & Case II & Case III \\
\hline & \multicolumn{3}{c}{ Goal values } \\
\cline { 2 - 4 } GM & $3,400.0$ & $3,400.0$ & $2,763.3$ \\
LAB & 591.4 & 628.1 & 498.3 \\
NSV & $84,800.0$ & $84,800.0$ & $67,745.9$ \\
WAT & $6,591.9$ & $7,363.2$ & $5,900.0$ \\
FER & 196.3 & 173.6 & 170.0 \\
\hline \multicolumn{4}{c}{} \\
\hline \multicolumn{4}{c}{ Deviational variables } \\
$\mathbf{n}_{1}$ & 0 & 0 & 636.7 \\
$\mathbf{p}_{2}$ & 0 & 0 & 0 \\
$\mathbf{p}_{3}$ & 0 & 0 & 0 \\
$\mathbf{p}_{4}$ & 691.9 & $1,463.1$ & 0 \\
$\mathbf{p}_{5}$ & 26.3 & 3.6 & 0
\end{tabular}

Case 1 Economic scenarios where water is $4^{\text {th }}$ priority, Case 2. Economic scenarios where water is $5^{\text {th }}$ priority,

Case 3. All environmental scenarios.

Apart from the sequence of priorities, sensitivity analysis also examines a set of different target values on alternative planning strategies. On this account, successive runs of the same LGP models were performed, each time with slight alterations of one target value $\left(g_{i}\right)$. These alterations were limited inside the interval between nadir and ideal values for each goal. The sensitivity analysis on target values is often utilized as a trade-off analysis that undertakes the investigation of interrelations between some pairs of objectives [15]. Figure 2 illustrates maybe the most interesting output from this analysis, as it displays the variation of water and nitrogen input at the solution point of the economic scenario, for different target values of gross margin. Both curves look like production functions and imply that there are options to improve the value of environmental objectives, sometimes at a small cost of the economic ones. On the other hand Figure 3 shows the trade-off between gross margin and labor at the environmental scenario, for different target values of total nitrogen. It clearly demonstrates the remarkable role of fertilizers on farmers' income and on primary sector 's employment, which indicates that significant incentives should be given in order to achieve an environmental sustainable agriculture.

\section{CONCLUSIONS}

It is well known that farmers' revenue is directly proportional to the use of irrigation water and fertilizer. This relationship could be harmful for the environment in highly intensified agricultural systems or in very sensitive areas. Thus, some target values must take place for both environmental and economic attributes.

According to the goal programming results, it is important to point out that the economic scenarios may not satisfy the environmental goals, but they end up to better numbers than the status quo. So the application of a multi-criteria analysis may lead to a win-win situation, irrespective of the weighting system of preferences. It should be also noticed that in this study, labor and risk are not found as restrictive factors to the accomplishment of the selected goals. 

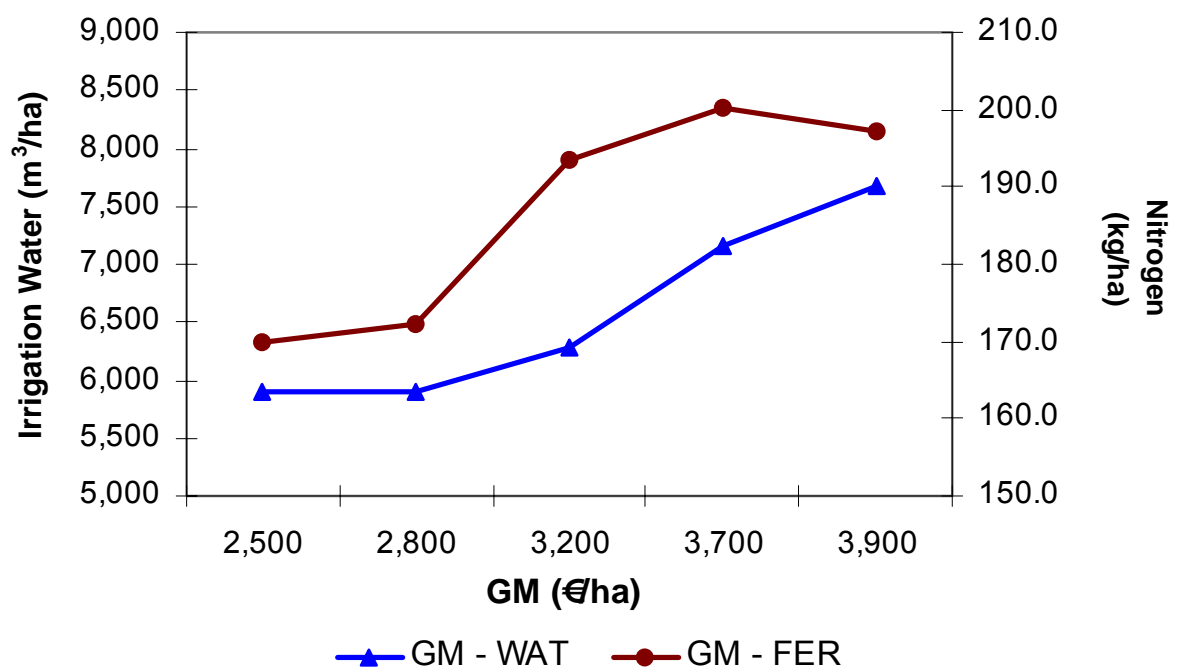

Figure 2. Gross margin sensitivity analysis

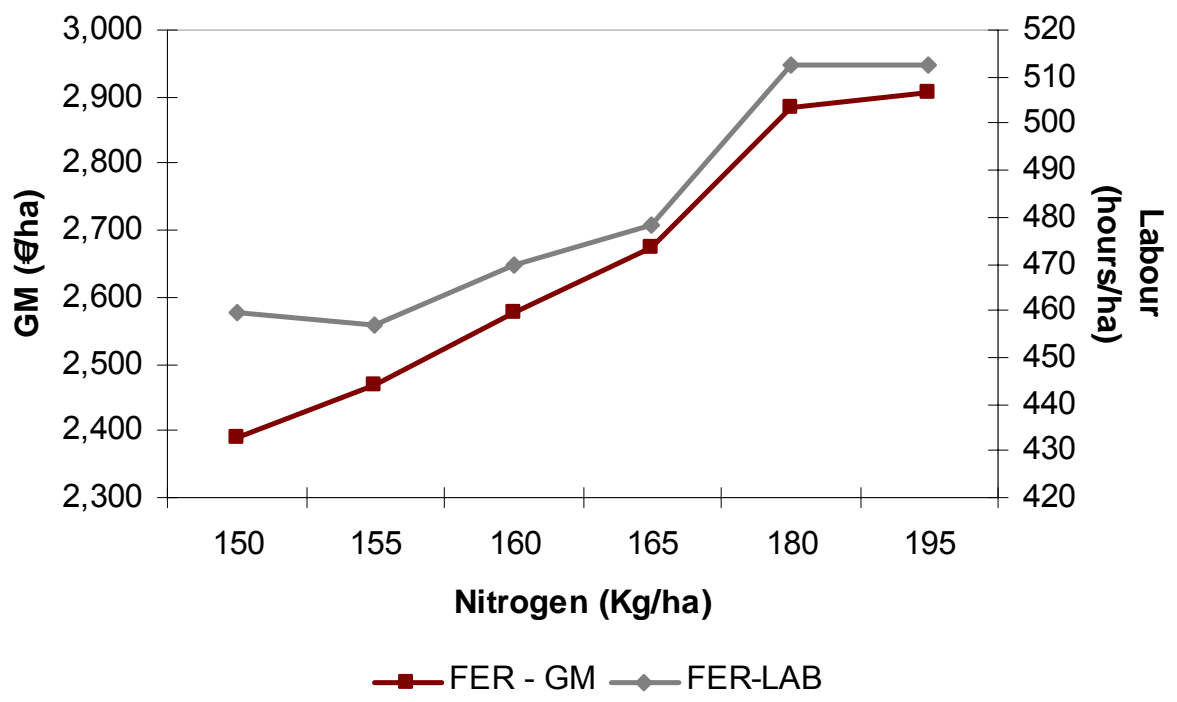

Figure 3. Fertiliser (nitrogen) sensitivity analysis

As analyzed throughout this paper, there is no unique solution or a solution that is overall accepted, but there is a number of possible resolutions that may arise by means of goal programming. These resolutions, to some extent, are subject to the perception and the intentions of the decision maker. So, attention should be paid on setting the goals, priorities and targets correctly and according to the characteristics of the reference area.

\section{ACKNOWLEDGEMENT}

The first author is a PhD student of the Department of Civil Engineering, AUTH, with a scholarship from the Greek State Scholarships Foundation.

\section{REFERENCES}

1. Guitouni A. and Martel J.M. (1998) Tentative guidelines to help choosing an appropriate MCDA method, European Journal of Operational Research, 109, 501-521.

2. Gomez-Limon J.A. and Berbel J. (2000) Multicriteria analysis of derived water demand functions: a Spanish case study, Agricultural Systems, 63, 49-72.

3. Sumpsi J.M., Amador F. and Romero C. (1996) On farmers' objectives: A multi-criteria approach, European Journal of Operational Research, 96, 64-71. 
4. Gomez-Limon J.A., Arriaza M. and Berbel J. (2002) Conflicting implementation of agricultural and water policies in irrigated areas in the EU, Journal of Agricultural Economics, 53(2), 259281.

5. Berbel J. and Rodriguez-Ocana A. (1998) An MCDM approach to production analysis: An application to irrigated farms in Southern Spain, European Journal of Operational Research, 107, 108-118.

6. Romero C. (2000) Risk programming for agricultural resource allocation: A multidimensional risk approach, Annals of Operations Research, 94, 57-68.

7. Hayashi K. (2000) Multicriteria analysis for agricultural resource management: A critical survey and future perspectives, European Journal of Operational Research, 122, 486-500.

8. Psychoudakis A., Aggelopoulos S. and Dimitriadou E. (2002) Agricultural land use in an environmentally sensitive area: An assessment of an agri-environmental policy measure, Journal of Environmental Planning and Management, 45(4), 481-491.

9. Tamiz M., Jones D.F., El-Darzi E. (1995) A review of goal programming and its applications, Annals of Operations Research, 58, 39-53.

10. Caballero R., Luque M., Molina J. and Ruiz F. (2004) MOPEN: A computational package for Linear Multiobjective and Goal Programming problems', Decision Support Systems, In Press.

11. Romero C. and Rehman T. (2003) Multiple criteria analysis for agricultural decisions, $2^{\text {nd }}$ edition, Elsevier Science B.V., Amsterdam, The Netherlands.

12. Tiwari D.N., Loof R. and Paudyal G.N. (1999) Environmental-economic decision-making in lowland irrigated agriculture using multi-criteria analysis techniques, Agricultural Systems, 60, 99-112.

13. Ignizio J.P. (1976) Goal Programming and Extensions, Lexington Books, Massachusetts.

14. Latinopoulos D. and Mylopoulos Y. (2004) Efficiency and equity considerations on irrigation water pricing: a case study in Loudias river basin. Inter. Confer. Protection and Restoration of the Environment VII, Mykonos, Greece.

15. Lu C.H. and Van Ittersum M.K. (2004) A trade-off analysis of policy objectives for Ansai, the Loess Plateau of China, Agriculture, Ecosystems and Environment, 102, 235-246. 